\title{
Pathogenic effects of Beauveria bassiana and Bacillus thuringiensis on the population dynamics of Ephestia Kuehniella
}

\author{
Negar Bahmani ${ }^{1}$, Masoud Latifian², ${ }^{*}$ Hadi Ostovan ${ }^{1}$ and Shahram Hesami ${ }^{1}$
}

\begin{abstract}
The most dominant pest of date stored in Khuzestan Province is Ephestia kuehniella Zeller (Lepidoptera: Pyralidae). In this study, the effects of Bacillus thuringiensis Kurstaki bacteria and Beauveria bassiana pathogenic fungi on the population dynamics of $E$. kuehniella date stock pest were investigated. To fulfill this, insectariums were kept in vitro at an average temperature of $27 \pm 5^{\circ} \mathrm{C}$ and a RH of $40 \pm 5 \%$ for a duration of 6 months, equivalent to the maximum permitted shelf life of date. For sampling from 3 heights in 3 rows, one hole was randomly selected and a sample equal to $20 \mathrm{~g}$ of date was taken. Three samples were taken from each insectarium. During 25-week storage period of date treated with B. bassiana and Btk, 6 outbreaks occurred in the population of E. kuehniella. The mechanism of the epidemic is in the way that, once the population has increased to a certain threshold, the incidence of the pathogenic epidemic will be mass-dependent, leading to a decreasing trend in the pest population. Therefore, population reduction was estimated to be at 6 to 32 times that of the control. The highest disease mortality rate occurred at the egg and larval developmental stages, so the pathogens caused the highest mortality before the population entered the reproductive stage. Gradually, from the egg growth stage to the complete insect stage, a reduction was observed in the number of individuals which entered the subsequent growth stage. At all stages, the reduction in the treatment population group was faster than the control population. The highest reduction in the number of individuals entering the next developmental stage was associated with the larval developmental stage, followed by developmental stages of the adult, pupal, and egg. Regarding the highest potential of B. bassiana and BtK in reducing the stock pest population, it is very possible to exploit this interaction for biocontrol.
\end{abstract}

Keywords: Date palm, Mill moth, Entomopathogens, Ephestia kuehniella, Pathogenic effects

\section{Background}

The production of date in Iran is more than one million two hundred thousand kilograms per year. Accordingly, Ephestia kuehniella Zeller (Lepidoptera: Pyralidae) is one of the most dominant stock pests of date palm in Khuzestan Province (Shakarami et al. 2015). The pest attacks stocked and stored date at the foot of the tree. Global attention is focused on minimizing spraying and control

\footnotetext{
*Correspondence: Masoud_latifian@yahoo.com

${ }^{2}$ Agricultural Research, Education and Extension Organization (AREEO),

Horticulture Science Research Institute, Karaje, Iran

Full list of author information is available at the end of the article
}

costs, which may be achieved by using low-cost biologically effective insecticides (Rehab et al. 2020). Microbial pesticides have been proposed as environmentally friendly insecticides due to their short half-life, high degradability, and selectivity over certain species, which is an advantage for pest control (Arthurs and Dara 2018). On the other hand, in developing countries such as Brazil (Mascarin et al. 2019) and India (Kumar et al. 2019), the biological pesticides are a growing in the market; the biological pesticide are still under the same regulation as chemical pesticides (Arora et al. 2020).

\section{Springer Open}

(- The Author(s). 2020 Open Access This article is licensed under a Creative Commons Attribution 4.0 International License, which permits use, sharing, adaptation, distribution and reproduction in any medium or format, as long as you give appropriate credit to the original author(s) and the source, provide a link to the Creative Commons licence, and indicate if changes were made. The images or other third party material in this article are included in the article's Creative Commons licence, unless indicated otherwise in a credit line to the material. If material is not included in the article's Creative Commons licence and your intended use is not permitted by statutory regulation or exceeds the permitted use, you will need to obtain permission directly from the copyright holder. To view a copy of this licence, visit http://creativecommons.org/licenses/by/4.0/. 
Various studies have been conducted on biological control of pests including fungal compounds (Latifian et al. 2018), bacterial and fungal combination (Mishra et al. 2013), and bacterial combination (Latifian and Kajbafvala 2015). Different strains of $B t$ bacteria and pathogenic fungi of insects have different synergistic effects on the pest control (Navon 2000 and Wraight and Ramos 2005). Recent trends in support of biological pesticides include the use of microbial agent mixtures (Sharifzadeh et al. 2018). This approach can lead to the prevention or delay in the development of insect resistance (Sudo et al. 2017), especially when the individual components of the preparation have different modes of action (Zhu et al. 2016). This strategy reduces costs (Das 2014) and preparation concentrations because microbial agent increases each other's activity and act synergistically (Wright and Ramos 2005). The two factors of host population density and pathogens have interactions and similarities in understanding the epidemiology of a disease among the insect population. In general, the population density of the pathogen is a mass-dependent factor (Gaugler and Kaya 1990).

Other research was conducted to evaluate the efficiency suitable Iranian isolate of $\mathrm{B}$. bassiana for the microbial control of the flour moth on date. Results as the first step of feasibility of fungus application in microbial control showed that it had high potential for application on control of flour moth in date (Bahmani et al. 2012). The $\mathrm{LC}_{50}$ of BtK on Batrachedra amydraula, E. kuehniella, and Plodia interpunctella were $2.15 \times 10^{8}, 5.18 \times$ $10^{8}$, and $2.71 \times 10^{8} \mathrm{CFU} / \mathrm{ml}$, respectively (Latifian and Kajbafvala 2015). The lethal concentration, compatibility, and interaction effects of $B t$ and B. bassiana on E. kuehniella had been studied under laboratory conditions. Spores of B. bassiana at all concentrations showed a good computability with $B t$. On the other hand, with increasing concentration of $B t$, the amount of compatibility index decreased. $B t$ had synergistic effects in all treatments but the highest synergistic effect was observed in $\mathrm{LC}_{50} B$. bassiana $+\mathrm{LC}_{50} B t$ mixing on moth larvae. Given the highest compatible potential of $B$. bassiana and $B t K$, the possibility of exploiting this synergy is highly efficient to produce biocontrol (Bahmani et al. 2020).

In this study, the combined effects of $B t$ bacteria and pathogenic fungus $B$. bassiana on the population dynamics of E. kuehniella were investigated under the date storage conditions.

\section{Materials and methods Proliferation of fungal agent}

The fungal isolate used in this study was obtained from research centers of date and tropical fruits of Iran. The characteristics of the studied isolate were IRAN 441C, which collected in Systan and Balochestan Province (Saravan) of Iran.

The pathogenic fungus was scraped by transfer needle after performing complete sporulation of the culture medium surface (12-14-day culture) (Johnson et al. 1992). The spores were collected in separate Erlenmeyer flasks containing $10 \mathrm{cc}$ of sterile distilled water with $0.05 \%$ Tween 80 solution. The abovementioned suspension was stirred in a pendulum for $5 \mathrm{~min}$ to uniformly distribute the spores. SDA + Y culture medium was used to increase the spore production (Thomas et al. 1987).

\section{Preparation of $B$. thuringiensis kurstaki inoculum}

Bacillus thuringiensis kurstaki (BtK) was used in this study. A pre-culture flask containing $500 \mathrm{ml}$ of medium was incubated at $30^{\circ} \mathrm{C}$ on an orbital shaker for $9 \mathrm{~h}$ and used to inoculate each of culture flasks. The composition of the pre-culture medium was as follows: glucose $(10 \mathrm{~g} /$ l), ammonium sulfate $(1.5 \mathrm{~g} / \mathrm{l})$, yeast extract $(2 \mathrm{~g} / \mathrm{l})$, K2HPO4 (1.5 g/l), KH2PO4 (1.5 g/l), CaCl2 $(60 \mathrm{mg} / \mathrm{l})$, $\mathrm{MgSO} 4$ (500 mg/l), and MnSO4 (50 mg/l). The medium $\mathrm{pH}$ was adjusted to 7.0 by $\mathrm{NaOH}$ and autoclaved at $120^{\circ} \mathrm{C}$ for $10 \mathrm{~min}$ (Azzou et al. 2015).

\section{Preparation of fungal and $B$. thuringiensis formulation}

Compatible formulation was produced at the production Strain Iran $441 C$ was formulated as an oil-based emulsionable suspension (sesame oil) containing $3.49 \times 10^{3}$ spores $/ \mathrm{ml}$. All preparations were stored at $4{ }^{\circ} \mathrm{C}$ and retained high initial viability (>93\%) for the duration of the study. Bt, formulated as a flowable concentrate (3.49 $\times 10^{3} \mathrm{CFU} / \mathrm{ml}$ ), was produced by Abbott Laboratories, Inc. of North Chicago, Illinois, and stored at room temperature until use. Viability of conidia was determined by direct observation of conidia ( $\times 400$ magnification) plated on agar containing yeast extract $(0.5 \%)$ and incubated $16-18 \mathrm{~h}$ at $25^{\circ} \mathrm{C}$. All conidia with visible germ tubes of any length were scored as viable (Wraight and Ramos 2005).

\section{Reproduction of E. kuehniella}

The flattened cap glass containers were used for reproduction of E. kuehniella in the laboratory. The container was heated to ensure that it was not infected. Every week, the female insects were transferred to new glass containers for laying. First, a growth medium was prepared for growing this moth. For this purpose, $1.5 \mathrm{~kg}$ of wheat flour plus $0.5 \mathrm{~kg}$ of bran were mixed with a small amount of yeast. After mixing, $1 \mathrm{~g}$ of moth eggs was poured on it and then covered with a clean cloth on a pan. By passing about 40 days, the first moths were observed and catching was begun. There were approximately 500 individuals of E. kuehniella inside each container, covered with a fine mesh cloth on the top of 
each container. A funnel or cylindrical container was placed in a short distance from the bottom of the sheets until the moths laid their eggs from the lattice holes on the bottom of the container on the sheet.

\section{Investigation of the pathogenic agents on the population dynamics}

The glass insectariums, which resembled the date stock in storage, were used for performing the experiments. These glass insectariums were $100 \times 5 \times 5 \mathrm{~cm}$. On the one side of the vertical surfaces, 9 holes were created in 3 different heights rows at $25-\mathrm{cm}$ intervals and were completely blocked by a special cap. Inside each of the insectariums was filled with $10 \mathrm{~kg}$ of Sayer date, about 500 dates each one weighing $20 \mathrm{~g}$. For the 6 insectarium experiments, three containers containing the best fungal and bacterial combination treated date with 50\% lethal concentration were considered, and the other three were considered as uninfected (as controls). Within each one of the insectariums, 250 full-sized E. kuehniella were transferred as the initial population. The insectariums were kept in vitro at the average temperature of $27 \pm 5{ }^{\circ} \mathrm{C}$ and relative moisture of $40 \pm 5 \%$ for a duration of 6 months, which was the maximum permitted shelf life of date stored. The temperature was adjusted by adjustable cooling and heating system at the constant temperature and moisture recording using a digital thermometer in the laboratory. The insectariums were sampled once a week.

\section{Sampling of the pest population within insectariums}

For sampling of each height, a hole was randomly selected from each row and a sample equal to $20 \mathrm{~g}$ of dates was taken. Three samples were taken from each one of the insectariums. The taken samples included different stages of pest growth. The following funnel was used to accurately evaluate the density of different growth stages of pests within the samples. For this purpose, $20 \mathrm{~g}$ of the sampled date from each one of the insectariums (including fungi and control containers) were individually transferred into a 250-ml Erlenmeyer flask, and then 20 g of sodium chloride, $30 \mathrm{ml}$ of caustic soda, and $40 \mathrm{ml}$ of water were added to it. Five milliliters of methylene blue was also added to the resulting mixture for staining. After that, the resulting mixture was transferred to a heat stirring machine until the mixture was boiling. After $2 \mathrm{~min}$ of boiling, the mixture was passed through a filtrate to separate the date pulps.

Various stages of pest development were transferred to New Erlenmeyer flasks with smoothing. Forty milliliters of odorless oil was added to Erlenmeyer flasks. Then, by the use of the separator funnel of this interstitial phase that included the growth stages of the pest population, different growth stages were counted by stereomicroscope. While studying the seasonal changes in different stages of population growth using age frequency data analysis method, different pest growth parameters under the treatment and control conditions were compared to determine the effect of the combined treatment on population dynamics.

\section{Data analysis}

The age frequency data were obtained from sampling in terms of the abovementioned method at different times from the number of E. kuehniella at different stages of growth (q stage or age). These data were used to calculate population parameters such as survival rate and period duration of each stage (Wootton and Bell 1992; Wisdom and Mills 1997) so that the sum of individuals entering each age stage, mean time elapsed between age 1 to q-1, probability of survival from age 1 to q-1 (survival rate of each stage), mean time of entry to each stage, and the rate of survival time were estimated. The interval between the 2 samplings was 6 months of constant sampling and 1 week. Therefore, we have the following:

$$
\hat{A}=\frac{1}{2} \sum_{1=1}^{n}\left(h_{i}+h_{i+1}\right) F_{i j}
$$

where Eq. (1), $F_{i j}$ is the number of individuals at the age of Ith afterwards at time $j . h_{i}$ and $h_{i+1}$ are the sampling intervals between the time $i$ and the next time (Wootton and Bell 1992 and Wisdom and Mills 1997). $q$ is the number of growth stages, $f_{j}(t)$ is number of population at stage $j$ for part of the population sampled at time $t . F_{j}(t)$ is the number at growth stages $j, j+1, q \ldots$ for part of the population sampled at time $t . M_{j}$ is the number that entered the growth stage $j$ for part of the population sampled at time $t . g_{j}(x)$ is the function of density probability entering the stage $j, \mu$ is mean time of entering stage $j, e^{-\theta}$ is the probability of survival, for one time unit, $a_{j}$ is growth stage duration $j, w_{j}$ is the survival rate, specific for age $j, A_{j}$ is the area under the age frequency curve of growth stage $j$, $A *_{j}$ is the area under the curve for growth stages $j, j+1, q$ ..., $D_{j}$ is the area under $t f_{j}(t)$ curve, and $D_{*_{j}}$ is the area under $t F_{j}(t)$ curve. $D_{j}$ depends on average time to enter the growth stage $j$, the survival parameter, $\theta$, and the area under the age frequency curve. These equations can be applied to age frequency cumulative data as follows (Wootton and Bell 1992 and Wisdom and Mills 1997):

$$
\begin{aligned}
& A *_{j}=M_{j} \theta \\
& D_{j} *=\left(\mu_{j}+\frac{1}{\theta}\right) A_{j} *
\end{aligned}
$$

Using the two above equations, the survival rate of each growth stage can be calculated as follows. Here $j$ is from 1 to $\mathrm{q}-1$. 


$$
w_{j}=\frac{A *_{j+1}}{A *_{j}}
$$

The survival parameter was as follows:

$$
\theta=-\ln \left(\frac{\frac{A *_{q}}{A *_{1}}}{\frac{D *_{q}}{A *_{q}}-\frac{D *_{1}}{A *_{1}}}\right)
$$

The stage $j$ period will be as follows. Where the value of $j$ varies from 1 to $\mathrm{q}-1$ :

$$
a_{j}=-\frac{1}{\theta} \ln \left(w_{j}\right)
$$

And the number that entered the stage $j$ (from 1 to $q$ ):

$$
M_{j}=A *{ }_{j} \theta
$$

When the sampling interval is equal, estimating the number between two times $i$ and $i+1$ enters the stage $\mathrm{i}$ and lived up to $i+1$ can be calculated by the following formula (Wootton and Bell 1992 and Wisdom and Mills 1997).

\section{Results and discussion}

The weekly changes in the population density at different growth stages of E. kuehniella eggs, larvae, pupae, and moths in the two control and treatment populations $(B$. bassiana $+B t K)$ under the storage conditions for a duration of 6 months were examined to be ensure that the results are presented in this topic.

\section{Growth stage of the pest egg}

There were two periods of activity in the population density change curve at this growth stage. The first period started from the 1st week and continued up to the 15th week. The peak of the egg density occurred around the 11th week. The second period started from the 16th week and continued up to the 24th week. The peak of the egg density during this period lasted about 22 weeks. A significant difference was found between the treatment and control conditions $(p=0.000036, z=$ 4.13 , and $\mathrm{df}=23$ ). The egg density during the 25 th week storage period was always significantly lower than the control conditions. Therefore, the maximum reduction was equal to 5.25 (Fig. 1).

\section{The larval developmental stage}

According to the curve shown in Fig. 2, during the 25week storage period, there were 2 periods of activities in the larval population density change curve. The first period started from the 1st week and continued up to the week 11 . The larval population density peak during this period was at week 6 .

The second period started from the 12th week and continued up to the 24th week, and accordingly, the peak of larval population density was during the 20th week. According to these results, a significant difference was found between the treatment and control conditions $(p=0.000013, z=4.36$, and $\mathrm{df}=23)$. The larval stage population density was always significantly lower in the treated date mass during the 25-week storage period compared to the control so that the maximum reduction was 5.36 times.

\section{Pupal developmental stage}

During the 25-week storage period, 2 periods of activities in the pupal population density change curve. The first period started from the 2nd week and continued up to the 13th week. The peak pupal population density was recorded at about the 8th week. The second period

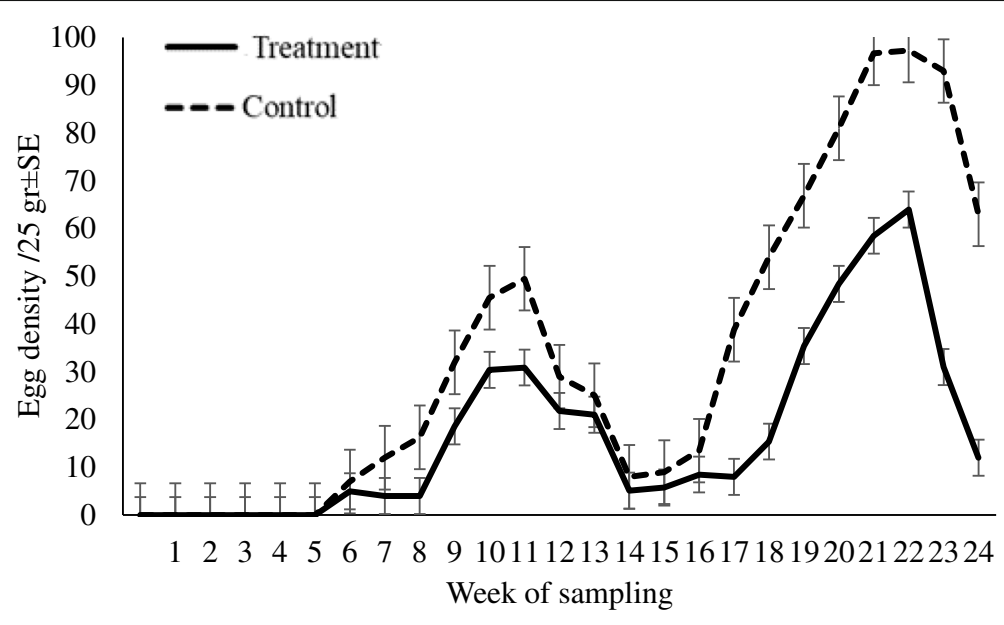

Fig. 1 The population density change curve of Ephestia kuehniella egg during 25 weeks of storage 


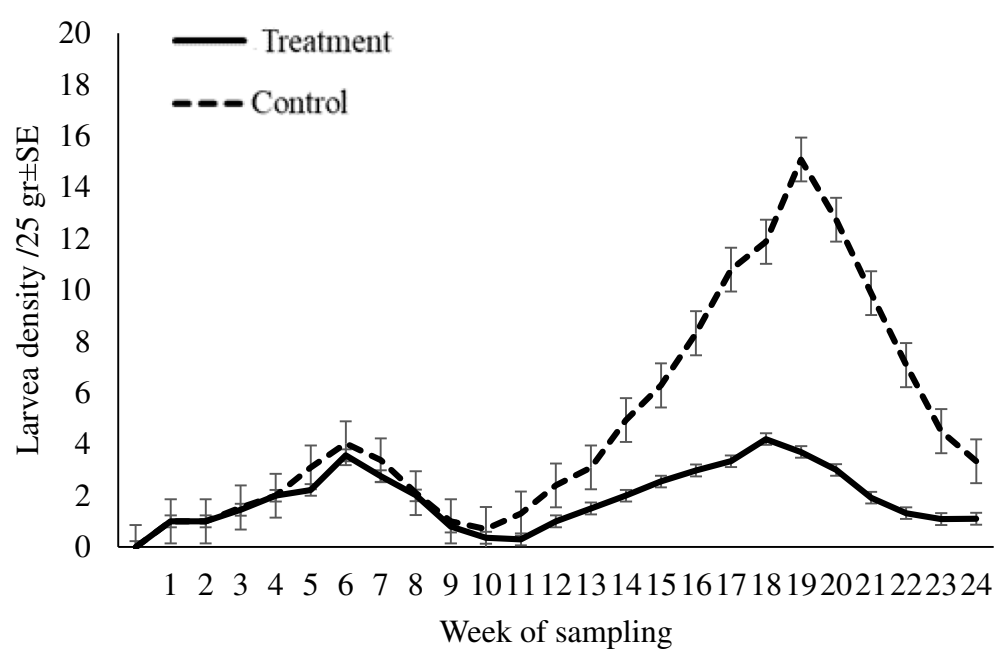

Fig. 2 The population density change curve of Ephestia kuehniella larvae during 25 weeks of storage

started from the 14th week and continued up to the 24th week (Fig. 3).

The peak population density of this period was recorded around the 21st week. According to these results, a significant difference was found between the treatment and control conditions $(p=0.00004, z=4.57$, and $\mathrm{df}=$ 23). During the 25-week storage period, the pupal population density of the pest was always significantly lower than the control conditions. Therefore, the maximum reduction was 4.2 times.

\section{Adult stage of insect growth}

During the 25-week storage, 2 periods of activities in the adult insect population density were change the curve. The first period started from the 4th week and continued up to the 15th week, and the peak was recorded at the 11th week. The second period started from the 16th week and continued up to the 24th week (Fig. 4).

Regarding, its peak occurred around the 22nd week. According to these results, a significant difference was found between the treatment and control conditions ( $p$ $=0.00002, z=4.25$, and $\mathrm{df}=23$ ). The population density of the adult insect was always significantly lower in the date treated during the 25-week storage period compared to the control so that the maximum reduction was 4.78 times.

\section{Analysis of age frequency data in the treatment and control populations}

The parameters of age frequency data for active population on the other cultivar treated with B. bassiana $+B t K$ and the control were fitted as shown in Table 1.

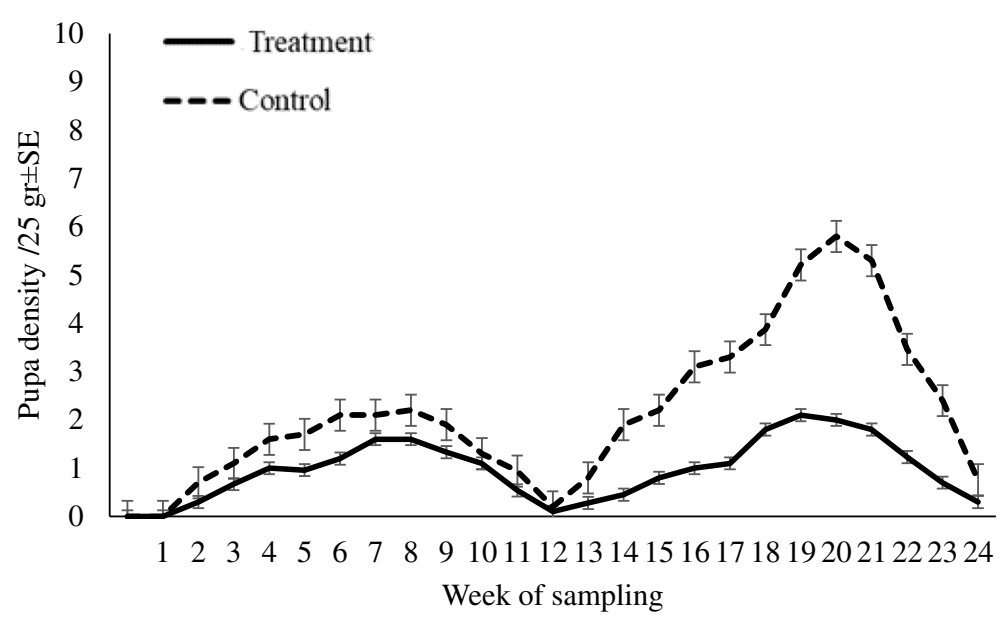

Fig. 3 The population density change curve of Ephestia kuehniella pupae during 25 weeks of storage 


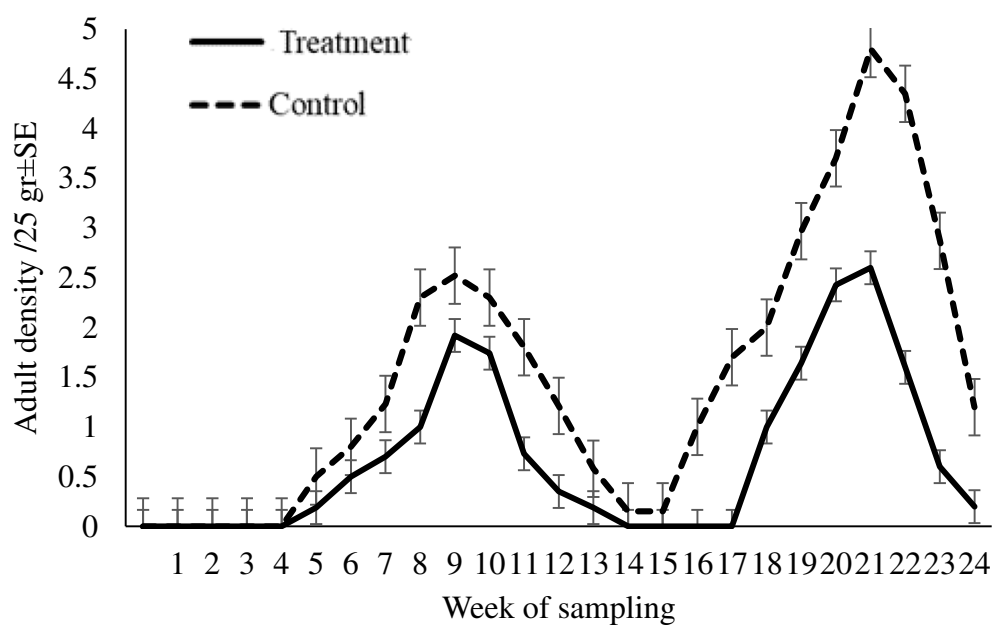

Fig. 4 The population density change curve of Ephestia kuehniella adults during 25 weeks of storage

In this table, $M_{j}$ is the number sampled that entered the growth stage $j$ for part of the population at time $t . a_{j}$ is the growth stage duration $j, w_{j}$ is the age-specific survival rate $j, b j$ is the number between two periods i and $1 i+$ entered the stage $i, D_{j}$ is the area undert $f_{j}(t)$ curve, and $A_{j}$ is the area under the curve at the growth stage $j$.

In Table 1 , the parameters $A j$ and $D j$ are the area of the age frequency curve and the area under $t f_{j}(t)$ curve, respectively, which are the keys to estimate the other parameters. $w_{j}$ is the population survival rate between the two growth stages. Comparison of this rate in the treatment and control populations indicated that the survival or transfer rate of the population from one growth stage to another stage during all stages except the larval stage in the treatment population is lower than the control population. In both of the populations, the highest mortality rate occurred from larval to pupal stages. In other words, the highest mortality occurred during the larval stage. Then, the highest mortality rate occurred during egg growing to the larvae. In other words, mortality at the egg stage was less important. This date was used to calculate the changes in populations treated with $B$. bassiana $+B t K$ for different growth stages. The highest survival rate was observed at the egg stage, and then at the larval and pupal stages, respectively (Fig. 5).

The parameter $a j$ in Table 1 shows the duration of the corresponding growth stage. The highest growth period was at the egg stage. Then, there were pupal and larval growth stages, respectively. The disease has caused a sharp reduction in the life span of all the growth stages. The highest reduction occurred at larval, pupal, and egg stages, respectively (Fig. 6).

The parameter $M j$ indicates the number of individuals entered the next growth stage. As shown in Table 1, a gradual reduction was observed in the number of individuals entered the growth stage from the egg growth stage to the adults. At all stages, the reduction in the treatment population was faster than the control population. The population reduction during different growth stages regarding the treatment with $B$. bassiana $+B t K$ was estimated (Fig. 7). According to this figure, the largest reduction in the number of individuals entering the next growth stage was related to the larval growth stage, followed by the adult, pupal, and egg growth stages, respectively.

Results as an application can be programmed through the release of a combination of $B$. bassiana $+B t K$ for

Table 1 Age frequency data parameters for the Ephestia kuehniella treatment and control populations

\begin{tabular}{|c|c|c|c|c|c|c|c|}
\hline Populations & Life stage & $\mathrm{Aj}$ & Dj & $\mathrm{Bj}$ & Wj & $\mathrm{Aj}$ & $\mathrm{Mj}$ \\
\hline \multirow[t]{4}{*}{ Treatment } & Egg & 508.96 & 8484.3 & 16.7 & 0.1686 & 0.717 & 1250.5 \\
\hline & Larvae & 87.16 & 1206.2 & 13.8 & 0.4686 & 0.305 & 210.87 \\
\hline & Pupa & 40.96 & 593.7 & 14.5 & 0.4181 & 0.351 & 98.78 \\
\hline & Adult & 17.2 & 268.5 & 15.6 & & & 41.29 \\
\hline \multirow[t]{4}{*}{ Control } & Egg & 1018.7 & $17,657.6$ & 17.3 & 0.196 & 1.062 & 1493.5 \\
\hline & Larvae & 212.55 & 3385.55 & 15.92 & 0.431 & 0.5493 & 293.41 \\
\hline & Pupa & 92.7 & 1443.25 & 15.67 & 0.420 & 0.566 & 126.48 \\
\hline & Adult & 39.5 & 626.55 & 15.8 & & & 53.11 \\
\hline
\end{tabular}




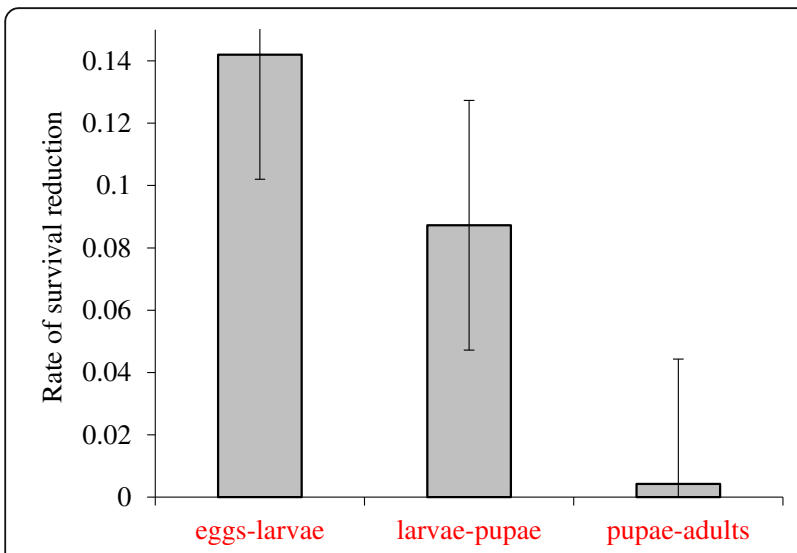

Fig. 5 Comparison of survival reduction rates in treated Ephestia kuehniella growth stages related to the control

the management of date storage pests. The population change studies showed that the combined treatment due to high mortality rate at the larval stage and preventing the emergence of adult is effective on the management of stored date pests. In addition, the functional combination of $B$. bassiana $+B t K$ suspension can result in better control of $E$. kuehniella compared to separately applying them. B. bassiana alone was not very effective on controlling the larval populations relative to other growth stages (Wraight and Ramos 2005). The time of population exposure to the control factor is also important. The results of the studies performed by other researchers suggested that repeated usage will be more effective under the conditions of high larval density (Johnson and Goettel 1993 and Inglis et al. 1996). In this study, a reduction of 5.36 times was observed at the growth stage of E. kuehniella larvae.

Of course, it should be noted that the control potential of $B$. bassiana is limited at high temperatures (Ekesi

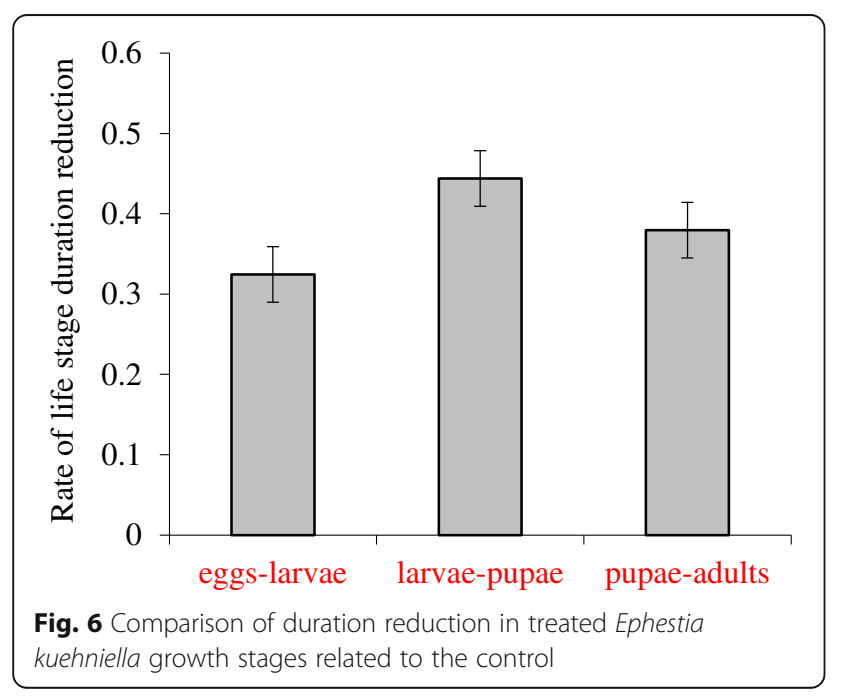

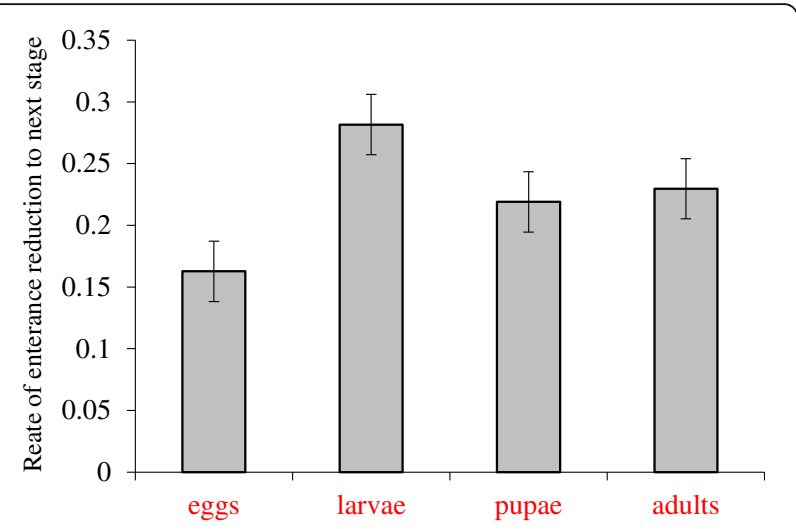

Fig. 7 Comparison of the entrance reduction rates in treated Ephestia kuehniella at growth stages related to the control

et al. 1999). Therefore, the effectiveness of B. bassiana can be increased by creating combined formulations such as $B t K$ in application. The highest survival of $B$. bassiana in date mass also allows the pests to be exposed to fungal spores more frequently than the bacteria.

There are several reports of the correlations between $B t K$ and $B$. bassiana. For example, the use of $B t$ of maize (Zea mays) increases the sensitivity of European maize beetles to $B$. bassiana. Also, the correlations between $B$. bassiana strain GHA and Bt. tenebrionis have been reported in the larval populations of Colorado potato beetles (Wraight and Ramos 2005). Several mechanisms have been proposed for the synergistic effects of $B$. bassiana and Bt. Some researchers have reported synergistic effects as a result of prolonging the time interval between molt due to endotoxin-induced toxins caused by $B t$ activity, thereby giving $B$. bassiana more time to penetrate the body cuticle before being eliminated (Wraight and Ramos 2005). On the one hand, larvae fed with food infected with $B$. bassiana spores acquired bacterial infection faster through the intestine ( $\mathrm{Ma}$ et al. 2008) and on the other hand, starvation has been reported to increase the sensitivity to $B$. bassiana spores, and $B t K$ disrupts the gastrointestinal tract in this way, spreading the epidemic in the host population infected with the fungus (Miranpuri and Khachatourians 1991).

The infection caused by the pathogenic activity of $B$. bassiana increases along with increase of the period between larval molt and reduction of intestinal cuticle excretion due to bacterial activity in the intestine. This mechanism may also explain the increased effect of $B t+$ $B$ bassiana. Endotoxin of bacterial activity in the early larvae provides the background for most pathogenic fungi to enter the gastrointestinal tract, by passing a few days from the bacterial entry and a synergistic background for the complete onset of pest disease and death before entering the pupae (Furlong and Groden 2001). 
The results of the present study obtained a pesticide based on the synergistic yield of $B t K$ and $B$. bassiana. Although other researchers have achieved similar results, there are different variables in each system that can have different effects on the final efficiency. Such differences have been observed in other researchers' studies (Costa et al. 2001). However, another important point is that, in addition to the isolates of $B$. bassiana and $B t$, the constituents of modern formulations for the production of biological pesticides should also be compatible with the pathogenic activity of the two species (Vandenberg et al. 1998).

The surfactants can also interfere with and enhance or weaken the insecticidal activities of $B$. bassiana and $B t$ (Morris et al. 1995). The surfactants can affect the intestinal epithelium of insects and increase its permeability to bacterial toxins. The use of moisturizing and emulsifying agents in the formulation of B. bassiana and $B t K$ aggravates the incidence of disease in target pests.

There are successful examples of the practical applications of B. bassiana and $B t K$ interactions for the pest management system. For example, for having a full control of potato Colorado beetles over a 6-year period, it has been shown that the resulting biological pesticides, while lower costs than conventional management practices, can be used as a method for controlling the key elements of a combined multiple pest management system for the management of potato Colorado beetles. Clearly, such biological control programs have the potential to reduce the selective pesticide resistance strains (Cloutier and Jean 1998).

Regarding the high adaptive potential of B. bassiana and $B t K$, it is possible to exploit this coexistence for producing highly efficient and cost-effective biological pesticides. The microbial pesticides are costly and any strategy that allows a reduction in concentration makes their application in combined pest management more attractive. B. bassiana is mostly affected by environmental factors and its duration is longer, while $B t K$ has a faster effect and a shorter duration. Therefore, the combination of these two can provide an appropriate control in many cases for pest larvae.

In general, the results of in vitro studies, which are the first step in the feasibility study of the use of $B$. bassiana and $B t K$ in microbial combined control of E. kuehniella, showed that the combination of B. bassiana and BtK is of high epidemiological potential. Also, further studies are needed to find the suitable formulations for the combination of $B$. bassiana and $B t K$ using vegetable oils and adding synergistic factors such as diatomaceous soil to its formulation because international experience has shown that vegetable oils are effective on enhancing the efficiency of formulations of insect pathogens. The diatomaceous soil also helps the host insect body to penetrate the fungus more rapidly and effectively by scratching the surface of the host body (Bell 1996). It is also necessary to investigate the effects of the combination of $B$. bassiana and $B t K$ compared to other physical and chemical control methods on developing the control management plans.

\section{Conclusion}

B. bassiana and $B t$ had a high adaptive potential different growth stages of E. kuehniella. It is possible to exploit this coexistence for producing highly efficient and cost-effective biological pesticides for date palm stored pests.

\section{Abbreviations}

SDA + Y: Sabouraud dexterose agar + yeast extract; 1 to q-1: Survival rate of each stage; $q$ : Stage or age; Fij: Number of individuals at the age of Ith afterwards at time $j_{i} h_{\mathrm{i}}$ and $h_{\mathrm{i}+1}$ : Sampling intervals between the time $i$ and the next time; $q$ : Number of growth stages; $f_{j}(t)$ : Number of population at stage $j$ for part of the population sampled at time $t ; F_{j}(t)$ : Number at growth stages $j_{1} j+1, q \ldots$ for part of the population sampled at time $t_{i} M_{j}$. Number that entered the growth stage $j$ for part of the population sampled at time $t$; $g_{j}(x)$ : Function of density probability entering the stage $j_{;} \mu$ : Mean time of entering stage $j ; e^{-\theta}$ : Probability of survival, for one time unit; $a_{j}$ : Growth stage duration $j_{i} w_{j}$ : Survival rate, specific for age $j_{i} A_{j}$ : Area under the age frequency curve of growth stage $j_{i} A *_{j}$ : Area under the curve for growth stages $j_{i} j+1, q_{\ldots} \ldots ; D_{j}$ : Area undertf $(t)$ curve; $D *$ : Area undert $F_{j}(t)$ curve; df: Degree freedom; $z$ : $z$ test; $p: p$ value; $M_{j}$. Number sampled that entered the growth stage $j$ for part of the population at time $t ; a_{j}$ : Growth stage duration $j ; w_{j}$ : Age-specific survival rate $j ;$ bj: Number between two periods $i$ and $1 i+$ entered the stage $i ; D_{j}$. Area undertf $f_{j}(t)$ curve; $A_{j}$. Area under the curve at the growth stage $j$

\section{Acknowledgements}

We would like to thank the team of Entomology Lab., date palm, and tropical research center of Horticultural Science Research Institute of Iran.

\section{Authors' contributions}

All authors read and approved the final manuscript. Negar Bahmani: carried out the pathological and population studies and help to drafting the manuscript. Masoud Latifian: epizootiological studies, culturing of entomopathogens' data analysis, and drafting the manuscription. Hadi Ostovan: help to drafting manuscription and data analysis. Shahram Hesami: help to dafting the manuscription and experiments.

Funding

No funding

Availability of data and materials

All data of the study have been presented in the manuscript, and high quality and grade materials were used in this study.

Ethics approval and consent to participate

Not applicable

Consent for publication

Not applicable.

Competing interests

The authors declare that they have no competing interests.

\section{Author details}

${ }^{1}$ Department of Entomology, Shiraz Branch, Islamic Azad University, Shiraz, Iran. ${ }^{2}$ Agricultural Research, Education and Extension Organization (AREEO), Horticulture Science Research Institute, Karaje, Iran. 
Received: 31 March 2020 Accepted: 23 June 2020

Published online: 14 July 2020

\section{References}

Arora S. Stanley J and Srivastava C (2020) Phosphine: an eco-friendly alternative for management of wheat storage insects. bioRxiv. https://doi.org/10.1101/ 2020.03.05.978486

Arthurs S, Dara SK (2018) Microbial biopesticides for invertebrate pests and their markets in the United States. J Invertebr Pathol 165:13-21

Azzou H, Kebaili-Ghribi J, Daoud F, Abdelmalak N, Ennouri K, Belguith-Ben Hassan $N$, Tounsi S, Rouis S (2015) Selection and characterization of Bacillus thuringiensis strains toxic against pyralid stored-product pests. J Ap Entomol 139:690-700

Bahmani N, Ostovan H, Latifian M, Hesami S (2020) Lethal strength and compatibility of Bacillus thuringiensis with Beauveria bassiana and Metarhizium anisopliae in stored date pest (Oryzaephilus surinamensis and Ephestia kuehniella) control. J Entomol Res In Press

Bahmani N, Ostovan H, Latifian M, Rad B (2012) Study the lethal doses of suitable isolate of Beauveria bassiana for microbial control of Ephestia kuehniella on Sayer date cultivar. Plant Prot J 4:67-81

Bell CH (1996) Alternatives: physical methods and emission reduction. In Bell, C.H. , Price, N., Chakrabarti, B. (Eds.), The methyl bromide issue (pp 323-329).

Cloutier C, Jean C (1998) Synergism between natural enemies and biopesticides: a test case using the stinkbug Perillus bioculatus (Hemiptera: Pentatomidae) and Bacillus thuringiensis tenebrionis against Colorado potato beetle (Coleoptera: Chrysomelidae). J Econ Entomol 91:1096-1108

Costa SD, Barbercheck ME, Kennedy G (2001) Mortality of Colorado potato beetle (Leptinotarsa decemlineata) after sublethal stress with the CryllIA deltaendotoxin of Bacillus thuringiensis and subsequent exposure to Beauveria bassiana. J Invertebr Pathol 77:173-179

Das SK (2014) Scope and relevance of using pesticide mixtures in crop protection: a critical review. IJESTR. 2(5):119-125

Ekesi S, Maniania NK, Ampong-Nyarko F (1999) Effect of temperature on germination, radial growth and virulence of Metarhizium anisopliae and Beauveria bassiana on Megalurothrips sjostedti. Biocontrol Sci Tech 9:177185

Furlong MJ, Groden E (2001) Evaluation of synergistic interactions between the Colorado potato beetle (Coleoptera: Chrysomelidae) pathogen Beauveria bassiana and the insecticides imidacloprid and cyromazine. J Econ Entomol 94:344-356

Gaugler R, Kaya HK (1990) Entomopathogenic nematodes in biological control. CRC Press, Inc, Boca Raton, Florida, U.S.A, p 365

Inglis GD, Johnson DL, Goettel MS (1996) Effects of temperature and thermoregulation on mycosis by Beauveria bassiana in grasshoppers. Biol Control 7:131-139

Johnson D L, Goettel M S, Bradley C, Van der Paauw H and Maiga B (1992) Field trials with the entomopathogenic fungus Beauveria bassiana against grasshoppers in Mali, West Africa, July, 1990. Pages 296-310 in Biologica Control of Locusts and Grasshoppers. C. J. Lomer and C. Prior, ed. CAB International, Wallingford, UK.

Kumar KK, Sridhar J, Murali-baskaran RK, Senthilnathan P, Kaushal SK, Dara S (2019) Arthurs microbial biopesticides for insect pest management in India: current status and future prospects. J Invertebr Pathol 165:74-81

Latifian M, Ghazavi M, Soleimannejadian E (2018) The role of temperature on the pathogenicity of Beauveria bassiana in populations of sawtoothed grain beetle, Oryzaephilus surinamensis (Coleoptera: Silvanidae) fed on stored date fruits. J Crop Prot 7:395-402

Latifian M, Kajbafvala GR (2015) Pathogenicity of Bacillus thuringiensis against three important date palm insect pests. Arab J Plant Prot 33:323-329

Ma XM, Liu XX, Ning X, Zhang B, Han F, Guan XM, Tan YF, Zhang QW (2008) Effects of Bacillus thuringiensis toxin Cry1Ac and Beauveria bassiana on Asiatic corn borer (Lepidoptera: Crambidae). J Invertebr Pathol 99:123-128

Mascarin GM, Biaggioni R, Delalibera I, Fernandes É, Luz C, Faria M (2019) Current status and perspectives of fungal entomopathogens used for microbial control of arthropod pests in Brazil. J Invertebr Pathol 165:46-53

Miranpuri GS, Khachatourians G (1991) Infection sites of the entomopathogenic fungus Beauveria bassiana in the larvae of the mosquito Aedes aegypti. Entomol Exp Appl 59:19-27

Mishra DS, Kumar A, Prajapati CR, Singh AK, Sharma SD (2013) Identification of compatible bacterial and fungal isolate and their effectiveness against plant disease. J Environ Biol 34:183-189
Morris ON, Converse V, Kanagaratnam P (1995) Chemical additive eVects on the eYcacy of Bacillus thuringiensis Berliner subsp. Kurstaki against Mamestra conWgurata (Lepidoptera: Noctuidae). J Econ Entomol 88:815-824

Navon A, Ascher KRS (2000) Bioassay of entomopathogenic microbes and nematodes. CABI publishing, p 324

Rehab A A, Dalia D, Lotfy E and Hemat Z M (2020). Field application of bioinsecticides on spiny bollworm, Earias insulana (Bosid.) on cotton by using recent low volume ground spraying equipment. Egypt Acad J Biolog Sci., 13(1):47-57.

Shakarami J, Eftekharifar R, Latifian M, Jafari S (2015) Insecticidal activity and synergistic effect of Beauvaria bassiana (Bals.) Vuill. And three botanical compounds against third instar larvae of Ephestia kuehniella Zeller. Res. Crops 16:296-303

Sharifzadeh MS. Abdollahzadeh G. Damalas ChA and Rezaei R (2018) Farmers' criteria for pesticide selection and use in the pest control process. Agriculture.8:24.

Sudo M, Takahashi D, Andow DA, Suzuki Y, Yamanaka T (2017) Optimal management strategy of insecticide resistance under various insect life histories: heterogeneous timing of selection and interpatch dispersal. Evol Appl 11(2):271-283

Thomas KCG, Khachatourians G, Langledew WM (1987) Production and properties of Beauveria bassiana conidia cultivated in submerged culture. Can J Microbiol 33:12-20

Vandenberg JD, Ramos M, Altre JA (1998) Doseresponse and age- and temperature-related susceptibility of the diamondback moth to two isolates of Beauveria bassiana. Environ Entomol 27(4):1017-1021

Wisdom MJ, Mills LS (1997) Sensitivity analysis to guide population recovery: prairie chickens as an example. J Wild Manag 61:302-312

Wootton TJ, Bell DA (1992) A metapopulation model of the peregrine falcon in California: viability and management strategies. Ecol Appl 2:307-321

Wraight SP, Ramos ME (2005) Synergistic interaction between Beauveria bassiana and Bacillus thuringiensis tenebrionis-based biopesticides applied against field populations of Colorado potato beetle larvae. J Inverteb Pathol 90:139-150

Zhu F, Lavine L, O'Neal S, Lavine M, Foss C, Walsh D (2016) Insecticide resistance and management strategies in urban ecosystems. Insects. 7(1):2

\section{Publisher's Note}

Springer Nature remains neutral with regard to jurisdictional claims in published maps and institutional affiliations.

\section{Submit your manuscript to a SpringerOpen ${ }^{\circ}$ journal and benefit from:}

- Convenient online submission

- Rigorous peer review

- Open access: articles freely available online

- High visibility within the field

- Retaining the copyright to your article

Submit your next manuscript at $\boldsymbol{\nabla}$ springeropen.com 